\title{
Recent developments, new trends in seed crushing and oil refining
}

\author{
Katalin KÖVÁRI ${ }^{1}$ \\ Bunge Europe Research and Development \\ Centre, Kvassay Jenö út 1. \\ Budapest, Hungary $\mathrm{H}-1095$ \\ Fax : (+36) 12175241 \\ $<$ katalin.kovari@unge.com>
}

\begin{abstract}
Oil processing was considered as slowly changing "traditional" industry but the recent decades' developments and trends resulted in a lot of changes initiated by market, industry, environment protection and consumer needs. Driving force of the developments were centralization of the industry, more and more concerns on environmental impact, increased importance of food-feed safety, and last but not least research and development activity together with improved analytical capabilities. The presentation gives an overview on the results achieved on the field of the following areas: the criteria of applicability of physical refining of seed oils, solutions for proper degumming, the effect of seed pretreatment and crushing conditions on the crude oil quality, the importance and role of bleaching and active carbon treatment, the proper practice of deacidification/deodorization.
\end{abstract}

Key words: seed pretreatment, physical refining, degumming, bleaching, transisomer fatty acid
Oil processing was considered as a slowly changing "traditional" industry, but the recent decades' developments and trends resulted in a lot of changes initiated by market, industry, environment protection and consumers needs.

First, the centralization of the industry resulted in high capacity, one-line production plants, which needed new developments in equipment and automation.

Secondly, more and more concerns of environment protection forced the operators to reduce the environmental impacts (waste water, solid waste, air pollution). This initiated the development and application of mild processes like physical refining.

Thirdly, the food/feed safety issues became the most important question after suffering several crises in Europe. Contaminants removal and keeping the nutritional value of the oils during the processing have become crucial.

Last but not least, the research and development activity together with the improving analytical capabilities enabled us to understand better the details of applied processes, the effect of the whole procedure from growing/ harvesting/transport/storage/crushing/refining on the quality of the final product.

The presentation gives an overview on the results achieved on the following areas:

- the criteria of applicability of physical refining of seed oils;

- solutions for proper degumming;

- the effect of seed pretreatment and crushing conditions on the crude oil quality;

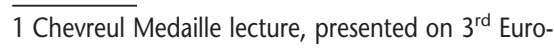
FedLipid Congress 5-8 September 2004.
- the importance and role of bleaching and active carbon treatment;

- the proper practice of deacidification/ deodorization.

\section{Criteria of applicability of physical refining of seed oils}

Physical refining has several advantages compared to the classical chemical one:

- improved yield;

- lower investment cost;

- less environmental impact (no soap stock to be treated, less waste water formed);

- mild refining (less chemicals used);

but this process is more sensitive to the crude oil quality [1].

The flow sheet of chemical and physical refining process is shown on the figure 1 and figure 2.

Applying physical refining means the increased importance of the oil pretreatment before distillative removal of free fatty acids.

One should ensure to eliminate phospholipids remaining less than $10 \mathrm{mg} / \mathrm{kg} P$ content in the oil after degumming and less than $4 \mathrm{mg} / \mathrm{kg} P$ after bleaching. In the same time to reduce iron and copper content below $0.1 \mathrm{mg} / \mathrm{kg}$ and 0.01 $\mathrm{mg} / \mathrm{kg}$ respectively. Crude seed oils, which have reached a certain level of oxidation, are difficult to refine. There are two more difficulties:

- removal of non-hydratable phospholipids;

- colour removal problems, sometimes when the auto-oxidation has really gone too far the so called "fix" colour formed, which is not removable by bleaching and/or heat bleaching.

\section{Solution \\ for proper degumming}

In the last decades a series of inventions have been implemented to the industrial practice (process and equipment as well) in the field of degumming giving chance to operators choose the most economic and environment friendly physical refining in the new installations.

The efficient removal of phospholipids is a key point.

Phospholipids are phosphoric acid diesters of glycerol where the phosphoric acid part is esterified by an alcohol (choline, etanolamine) or a polyol (inozitol).

If the phosphoric acid is not linked to any alcohol it is named phosphatidyl acid.

While the phosphatidyl choline (PC) and phosphatidyl inozitol (PI) are completely hydratable phosphatidyl ethanolamine (PE) is only partly and phosphatidyl acid (PA) is not hydratable, when they form salt with divalent cations $(\mathrm{Ca}++, \mathrm{Mg}++)$ or when they are in non dissociated form.

The efficient degumming process should convert the non-hydratable phospholipids (NHP) into hydratable ones and remove by hydrating and separation.

The simplified chemistry is the following:

- the phosphatide/metal complexes are decomposed by acid addition or using complexing agent; 


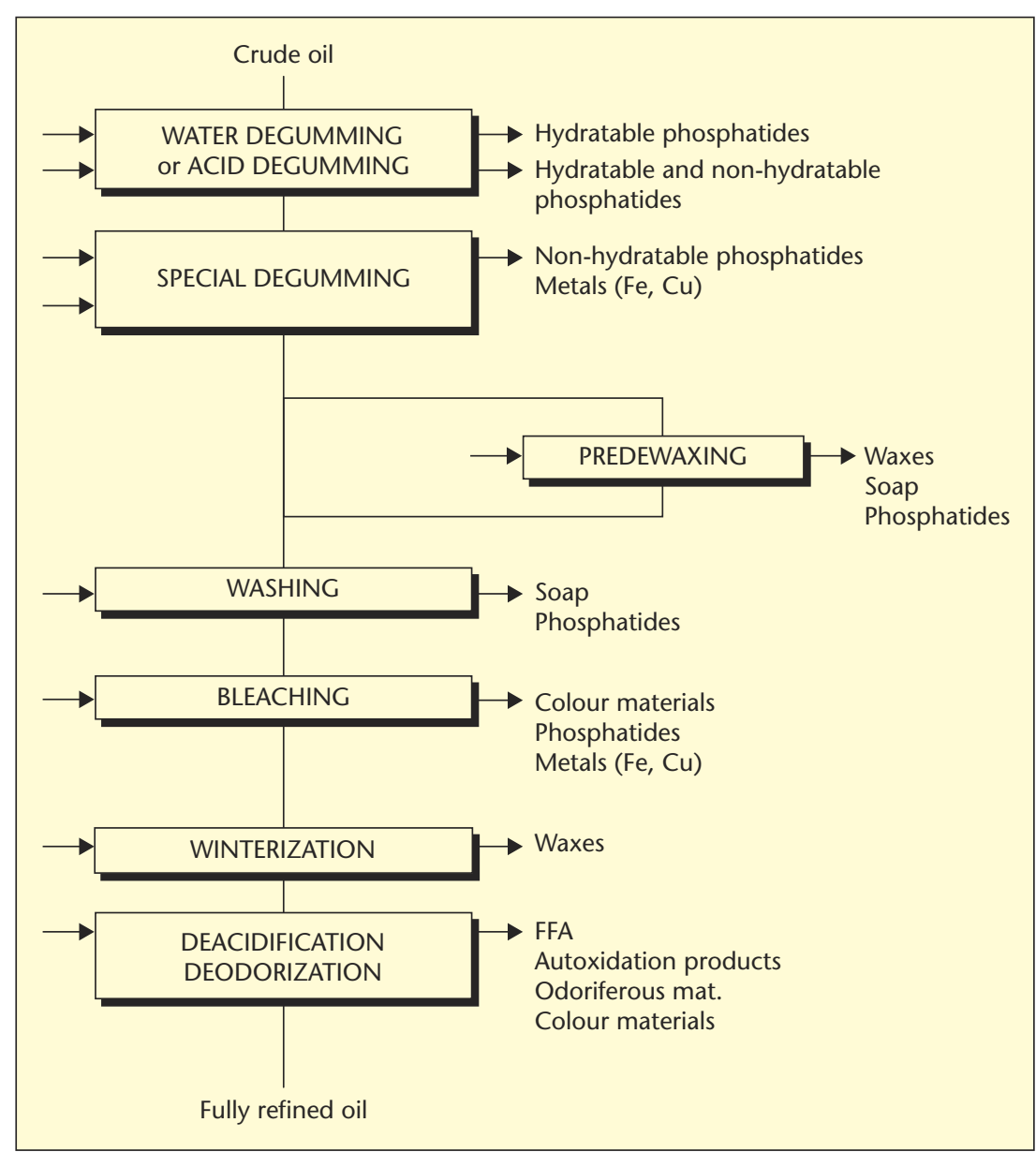

Figure 1. Chemical refining.

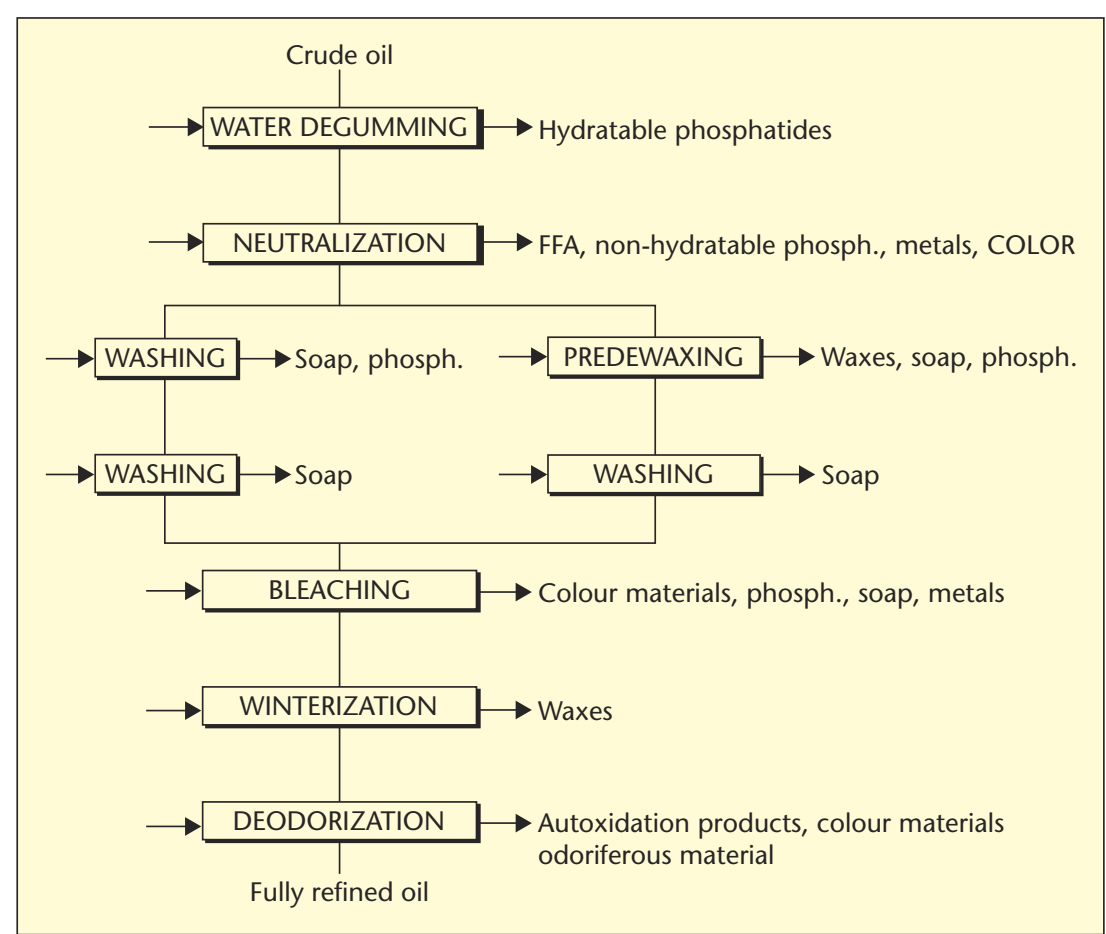

Figure 2. Physical refining.
- hydration of phospholipids by adding water; - partial neutralization and/or cooling is applied to avoid migration of phosphatides back to the oil phase or using emulsifier;

- holding time for agglomerate phospholipids.

Usually citric acid is used not only for decomposition of metal salt but as a chelating agent to keep the metals in water-soluble complex. In industrial applications UF degumming (Krupp-Cereol) superdegumming, unidegumming (Unilever), TOP degumming (Vandermoortele) and Enzymax process (Lurgi) and SOFT degumming (Tirtiaux) patents are used [2-8]. Each of them ensure sufficient removal of phospholipids but certainly there are differences in special equipment need and/or chemical usage (for detailed description of the core of the processes see table 1).

The Enzymax process uses phospholipase enzymes for converting non-hydratable phospholipids into lyso phospholipids, which are more soluble in water phase. Originally phospholipase $A_{2}$ was used, today there are phospholipase $A_{1}$ also available (effect of enzymes is shown on the figure 3 ).

Our company committed to meet environmental protection and mild processing has been applied:

- physical refining for sunflower and rapeseed oil first in Europe using UF degumming, and in the case of sunflower oil later the UF degumming has been modified applying predewaxing as well;

- first industrial application of enzymatic degumming;

- industrial application of enzymatic degumming in physical refining of soybean oil: stable, robust process, better yield.

Going further we carried out investigations on non-hydratable phospholipid formation during crushing in order to improve the process to produce better crude oil for physical refining.

\section{Effect of seed pretreatment and crushing condition on the crude oil quality}

As the crushing, mainly the seed pretreatment process defines the crude oil quality, we carried out survey of different crushing plants for better understanding the effect of conditions.

The aim is to optimize the process in order to keep the nutritional value, to prevent the formation of non-desirable compounds. There is a risk of increased enzyme activity provoked by destruction of seed structure, interaction with heat, humidity (water) and air (oxygen).

Increased activity of lipases increases the free fatty acid content (FFA). Increased activity of Phospholipase D produces phosphatidyl acid, which can form salt with $\mathrm{Ca}, \mathrm{Mg}$ or Fe ions 
Table 1. Special degumming processes.

\begin{tabular}{|c|c|c|c|c|}
\hline Patent owner & Process & Raw material & Core of process & Residual phosphor \\
\hline \multirow[t]{2}{*}{ Unilever } & 1. Superdegumming & Crude or water degumming oil & Heating, acid addition cooling, holding & $30-50 \mathrm{ppm}$ \\
\hline & 2. Unidegumming & Superdegummed oil & Lye addition, cooling, holding & $<10 \mathrm{ppm}$ \\
\hline Vandemoortele & TOP degumming & Crude or water degummed oil & $\begin{array}{l}\text { Heating, acid addition, special dynamic } \\
\text { mixing, lye addition, special two-step- } \\
\text { separation, washing, drying }\end{array}$ & $<10$ ppm \\
\hline Lurgi & Enzymax process & Crude or water degummed oil & $\begin{array}{l}\text { Heating, Ph adjustment (acid and lye } \\
\text { addition), enzyme addition, holding, } \\
\text { recycling, special mixing }\end{array}$ & $<10$ ppm \\
\hline Krupp/Cereol & UF degumming & Crude or water degummed oil & $\begin{array}{l}\text { Heating, acid addition, lye addition, cooling, } \\
\text { holding separation }\end{array}$ & $<10$ ppm \\
\hline Tirtiaux & SOFT degumming & Crude or water degummed oil & $\begin{array}{l}\text { Heating, acid, lye, EDTA complexing agent, } \\
\text { emulsifier addition, high shear mixing }\end{array}$ & $<10$ ppm \\
\hline
\end{tabular}

$$
\mathrm{R}_{2}-\mathrm{CO}+\mathrm{O}-\mathrm{CH}_{\mathrm{CH}_{2}}-\mathrm{O}-\mathrm{CO}-\mathrm{PO}-\mathrm{CO}
$$

$\mathrm{X}$ : $\mathrm{H}$, ethanolamine, choline, inozitol, serine...

Figure 3. Enzyme action.

increasing the non-hydratable phospholipid content in the crude oil. Lypoxigenase enzyme activity produces oxidized triglycerides and phospholipids with oxidized fatty acid chain, causing difficulties in $\mathrm{P}$ removal and bleaching. Mirozinase activity increases the $S$ containing compounds in crude oil.

We have investigated the non-hydratable phospholipid (NHP) and free fatty acid (FFA) formation in crushing under industrial circumstances.

Results of the survey carried out in two different crushing plants are shown on the figures 4-5. The proper heating rate in the pretreatment in a new crushing plant resulted in only a moderate increase of NHP and FFA, while in the case of old crushing plant the slow temperature increase during the pretreatment gave a chance for the enzymes to act and to form undesirable compounds resulted in higher increase NHP and FFA.

The results show the importance of the deactivation of enzymes prior to conditioning to pressing and extraction.

The critical process zone is the temperature range between $40-70{ }^{\circ} \mathrm{C}$ where the enzymes are active, so $70^{\circ} \mathrm{C}$ should be reached as quickly as possible.
An attractive solution for enzymes deactivation in the whole seed before crushing is to apply Exergy process (GEA) in the seed pretreatment [9]. This is a very short term, intensive steam treatment, which results in no enzyme activity can be provoked after destruction of seed structure (principle of the process is shown on figure 6). The Exergy process has been applied in one of our crushing plant. Survey carried out after the implementation has shown very good results (figure 7): extremely low NHP content, which allows us to use only water degumming before physical refining.

Using Exergy in the seed pretreatment results in different phospholipid composition in the crude oil, consequently in the lecithin as well (figure 8).

With Exergy the PA content very low, PC content high, so the hydratability of the phospholipids has been increased and the nutritional value of the lecithin is improved.

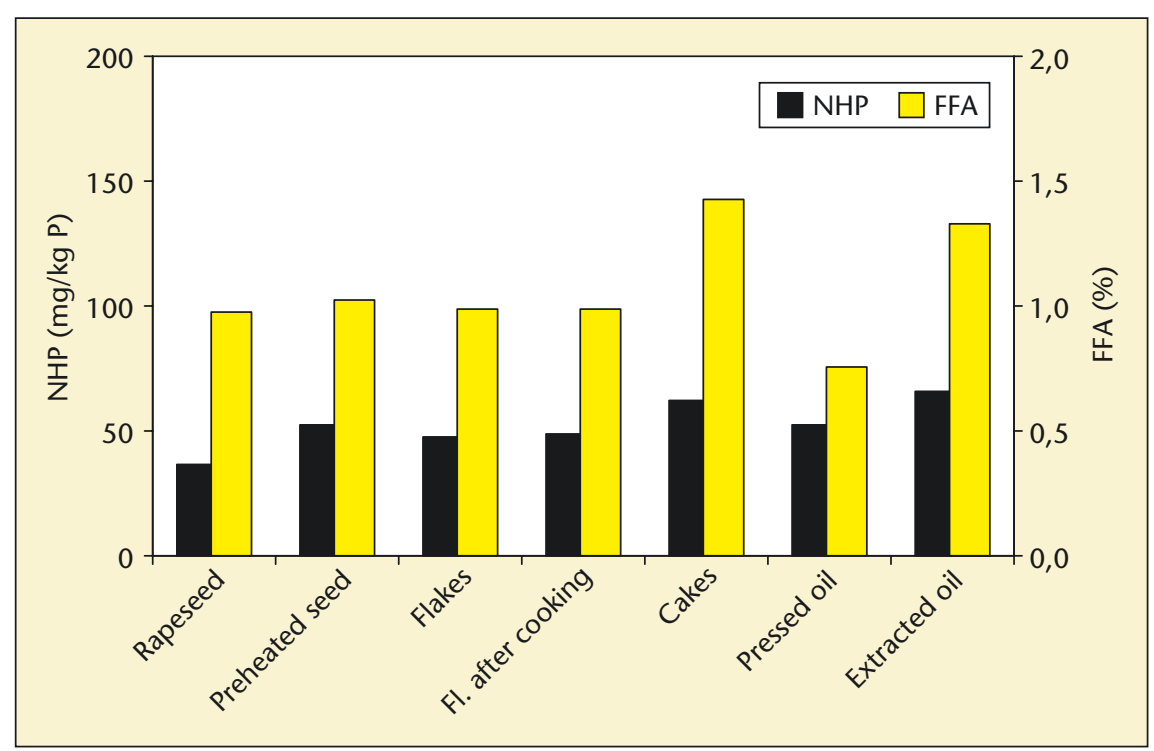

Figure 4. Survey 1, new crushing. 


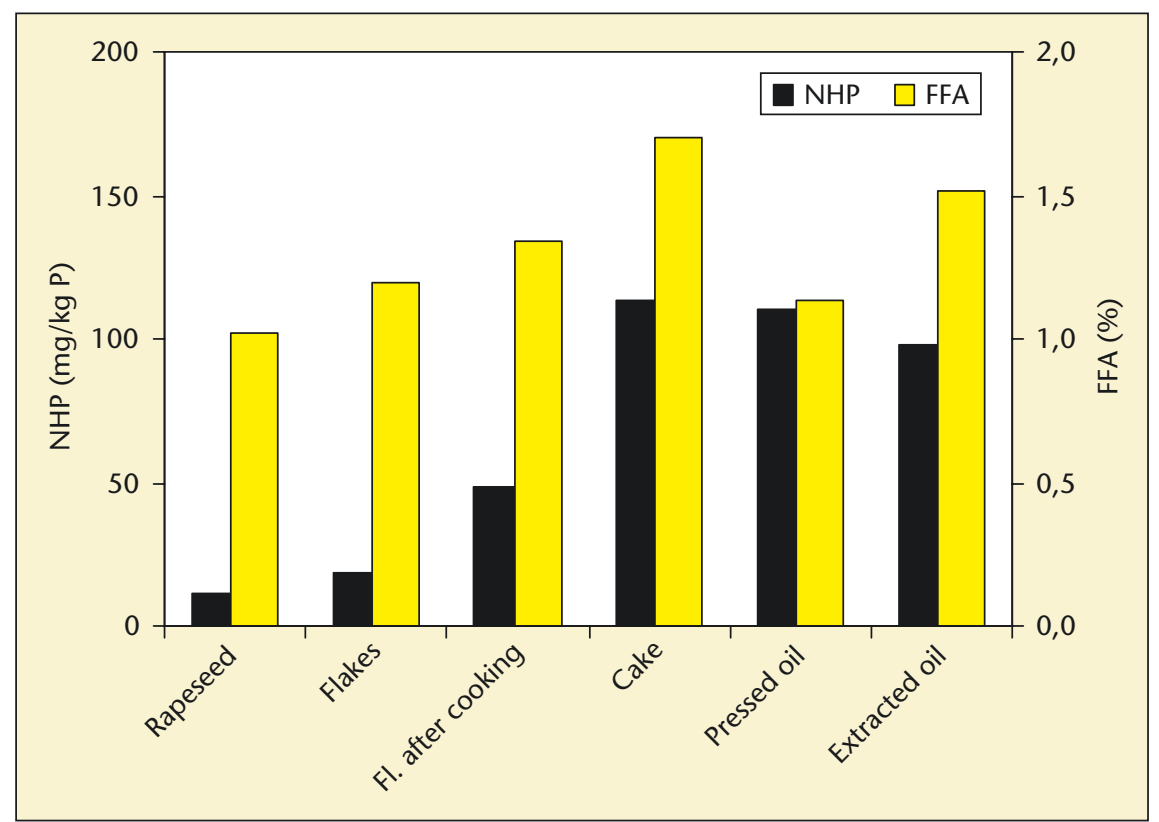

Figure 5. Survey 2

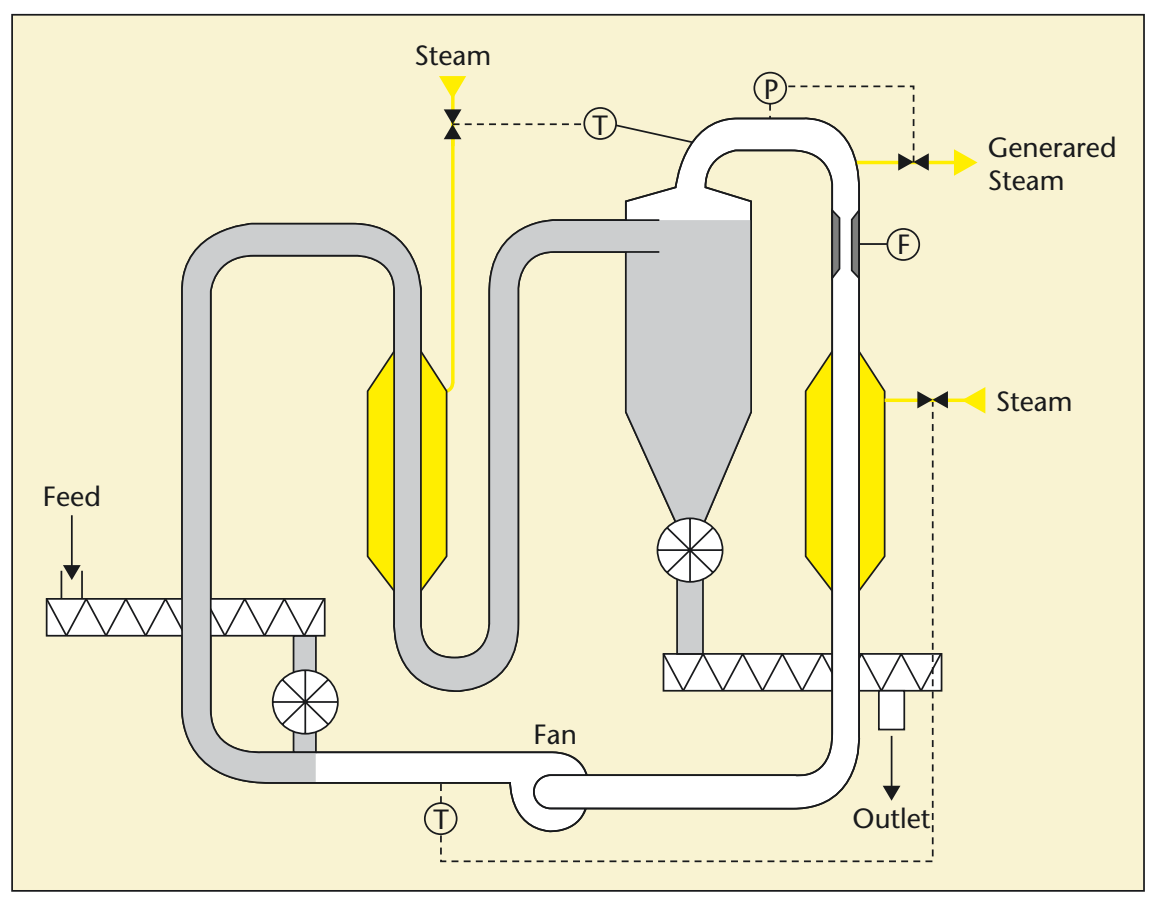

Figure 6. Exergy

\section{Importance and role of bleaching}

Bleaching as a part of the "traditional" chemical refining was originally employed to improve the colour [10]. Today with the wider application of physical refining and the more and more strict food safety regulation it should be considered as a tool to remove or convert undesirable compounds and contaminants as well.

The goal is maximum removal of undesirable compounds with minimum changes in major and valuable minor constituent of the oils.

According to their origin, the compounds to be removed can be divided into 3 groups:

- natural compounds (e.g. plant pigments, phospholipids);
- environmental contaminants (e.g. metals, pesticides, polyaromatic hydrocarbons (PAH's)...

- by-products formed during storage, processing, together with chemicals used in refining process and their derivates (trace metals, soap, oxidation by products).

Bleaching is a relatively simple process using the following adsorbents:

$\begin{array}{ll}\text { - natural clay } & \text { for removal pigments } \\ \text { - activated clay } & \text { for soap and } \\ \text { - silica } & \begin{array}{l}\text { phospholipids removal } \\ \text { - activated }\end{array} \\ \text { for PAH's removal }\end{array}$

carbon

As bleaching earth accelerates oxidation due to its high specific surface and catalytic activity, the Good Manufacture Practice is crucial to protect the oil from oxidation.

Do not forget that there are two sides to bleaching: inadequate operation conditions or overdosing the activated clay may have adverse effect.

The selection of appropriate bleaching material and to define the optimum dosage are not only economical issues (bleaching is the most costly refining step) but oil quality issue as well.The principal information we need to design the bleaching is the adsorption capacity of a certain bleaching material for the given plant colouring or contaminants (Freundlich isotherm).

In practice we have to remove a series of contaminants in one operation. It would be useful to have literature data for all the individual adsorption isotherm - but only a few available.

\section{Chlorophyll related pigment removal}

Operators are frequently faced with the problem: having the same level of plant colourings (Chlorophyll related pigments) in the rape oil to be bleached - different specific dosage needed for different oil lots.

Why? To better understand the process details and to improve the performance and the economy of the bleaching we investigated the changes in Chlorophyll related pigments during processing (HPLC analysis of their content and composition as well) and their adsorptive removal (isotherms, adsorption capacity of different bleaching materials).

Results show that Chlorophyll "a" and "b", which are characteristic to the seed are transformed mainly to pheophytin " $a$ " and " $b$ " during crushing.

Higher the applied temperature during the pretreatment step higher the portion of pyroand " $\mathrm{b}$ " compounds. 


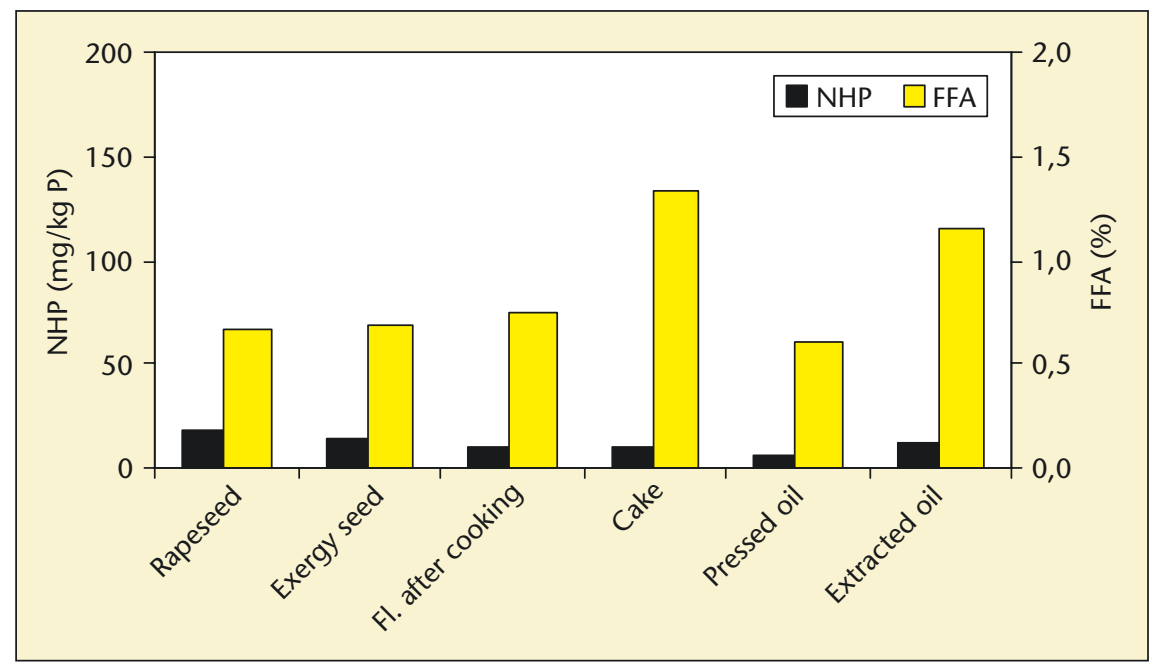

Figure 7. Survey 3.

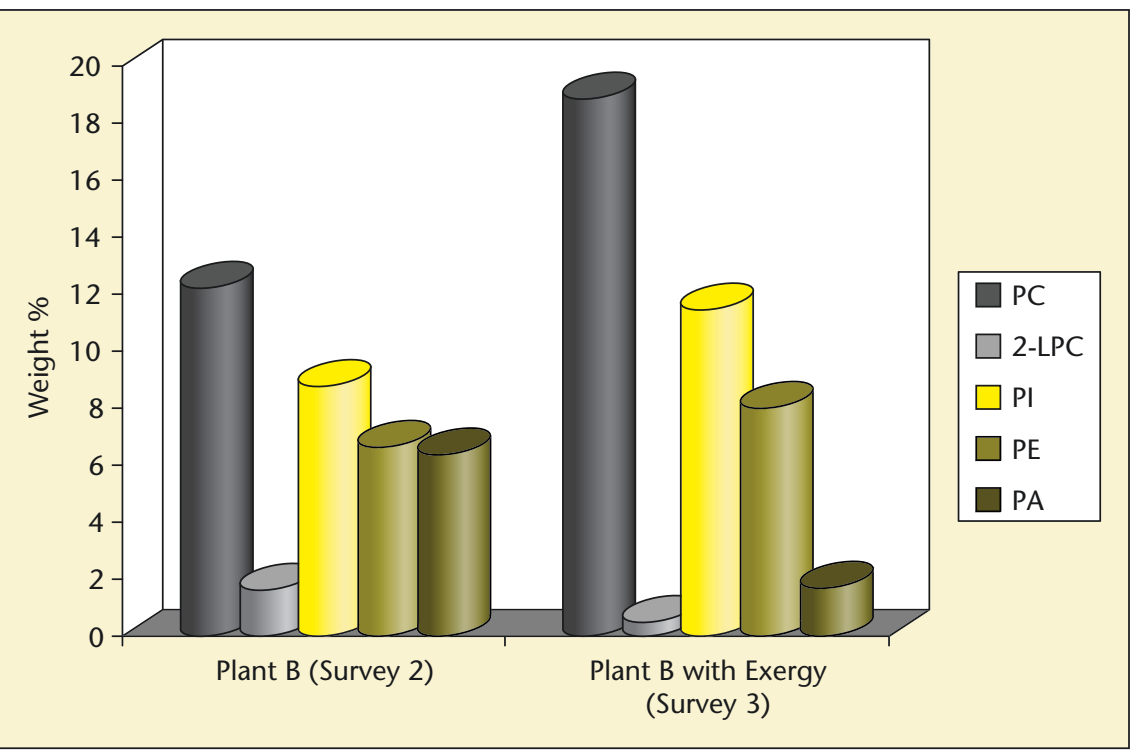

Figure 8. Crushing process and lecithin PL composition.

(Degradation of Chlorophyll into pheophytins is shown on figure 9.)

Laboratory scale bleaching test with different raw materials showed that bleaching earth has higher activity towards "a" compounds (figure 10) Defining a series of isotherms we concluded that the ration of " $a " \mid$ " $b$ " compounds has a definitive effect on the isotherms. So the optional bleaching earth addition is determined not only by the total concentration but also the composition of Chlorophyll related pigments.

To improve the bleaching performance we proposed to use "a"/"b" ration as a quality indicator. responsible for "fixed colour" and can not be removed by adsorptive methods. We recommended to use as quality indicator the UV-VIS spectra (figure 11). The bleaching earth dosage increase is not recommended, it does not improve the colour but the overdosed bleaching earth can act as pro-oxidant material. It can lead to less stable oil and high risk of taste/flavour reversion in fully refined oil during storage.

The only solution is to pay more attention to protecting the oil during storage and processing.

\section{Polyaromatic hydrocarbons removal by Active Carbon treatment}

Polyaromatic hydrocarbons (PAH's) are carcinogen contaminants, originated from the environmental pollution or in proper practice of drying seeds (direct fuel gas drying, which is already forbidden in Europe).

The use of active carbon in the bleaching is the only solution for removing heavy PAH's. To define the optimal Active Carbon usage Freundlich isotherms were determined for two different active carbon products (figure 12). We used Benzo-a pyren content determination as a marker for PAH's, the target is max. $1 \mathrm{mg} / \mathrm{kg}$ $\mathrm{BaP}$ content in the refined oil.

\section{Proper practice of deacidification/ deodorization}

The high temperature steam (or nitrogen) distillation under very low pressure (1-3 mbar) is the core process in physical refining. From the well pretreated oil the free fatty acids are removed by distillation and in the same operation we have to remove the volatile flavour, smell compounds, oxidative by-products as well as contaminants (light PAH's, pesticide, $P\left(B^{\prime} s\right.$ ) meanwhile keeping the nutritional value. In the last decades more and more attention is paid to the risk of trans isomer fatty acid formation during desodoration.

Nutritional studies have reported that trans isomer fatty acids in the diet increase the risk of cardiovascular diseases.

The good manufacture practice in deodorization/ deacidification is very important to fulfill all the targets: removal FFA, removal contaminants, long shelf life, taste stability, heat bleaching and the meantime to keep the trans isomer fatty acid level and the tocopherol loss at the minimum.

This should be reached only by compromising the working conditions.

The kinetic of geometrical isomerization of fatty acid has been studied under deodoriza- 


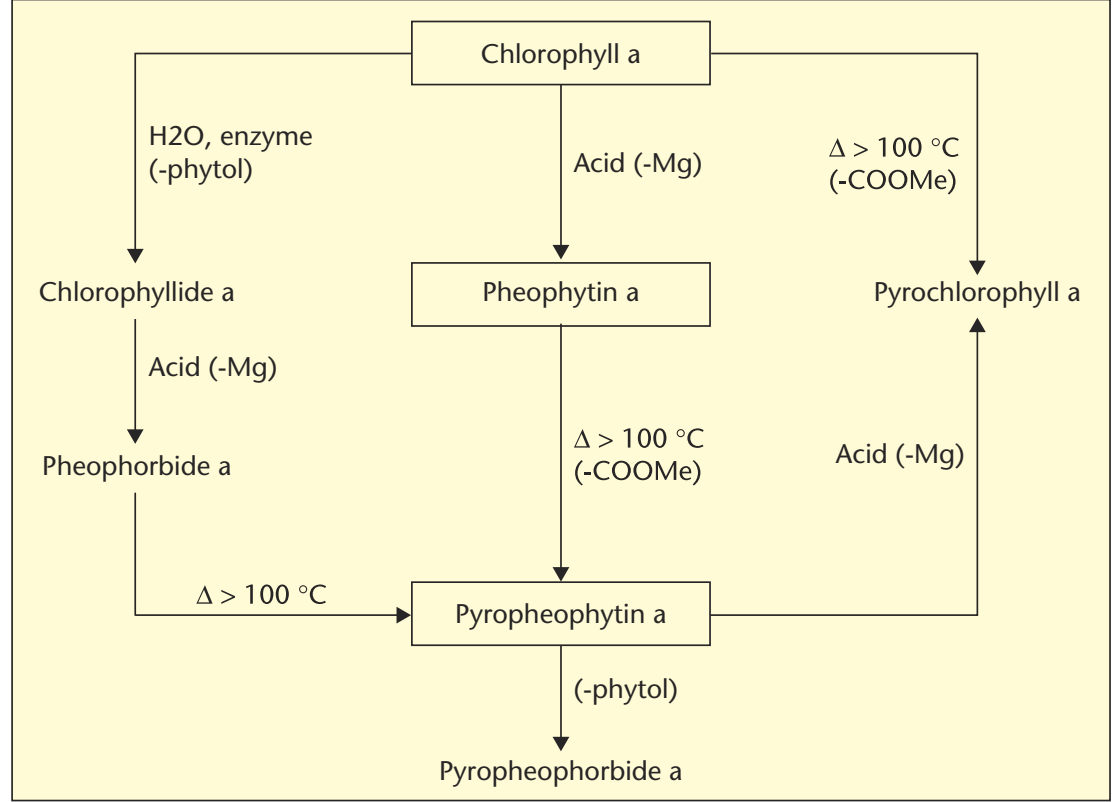

Figure 9. Degradation of Chlorophyll.

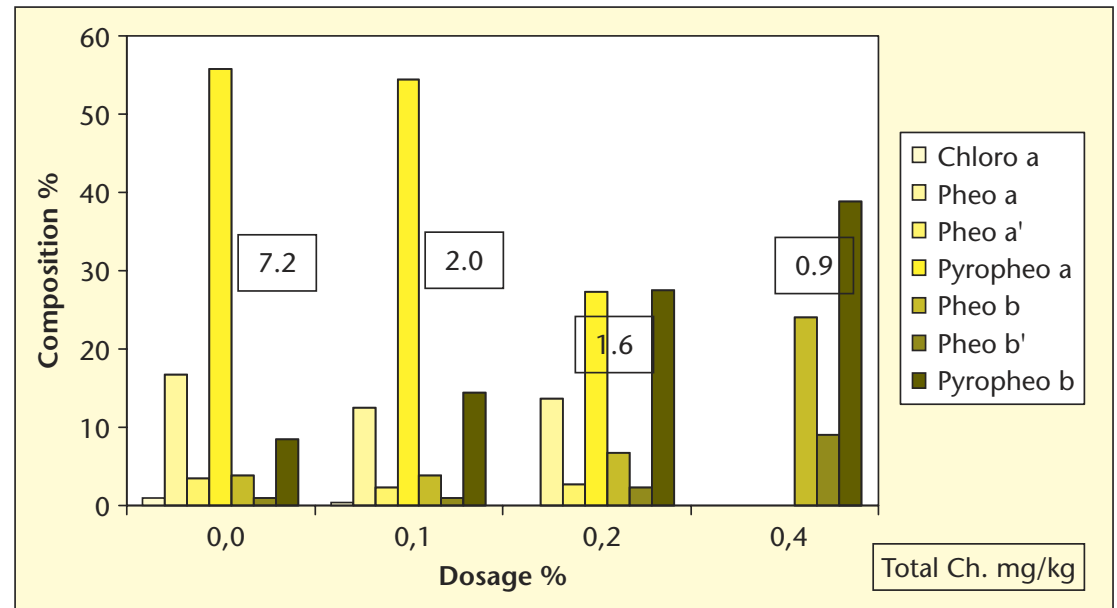

Figure 10. Changes in Chlorophyll related pigment composition during bleaching.

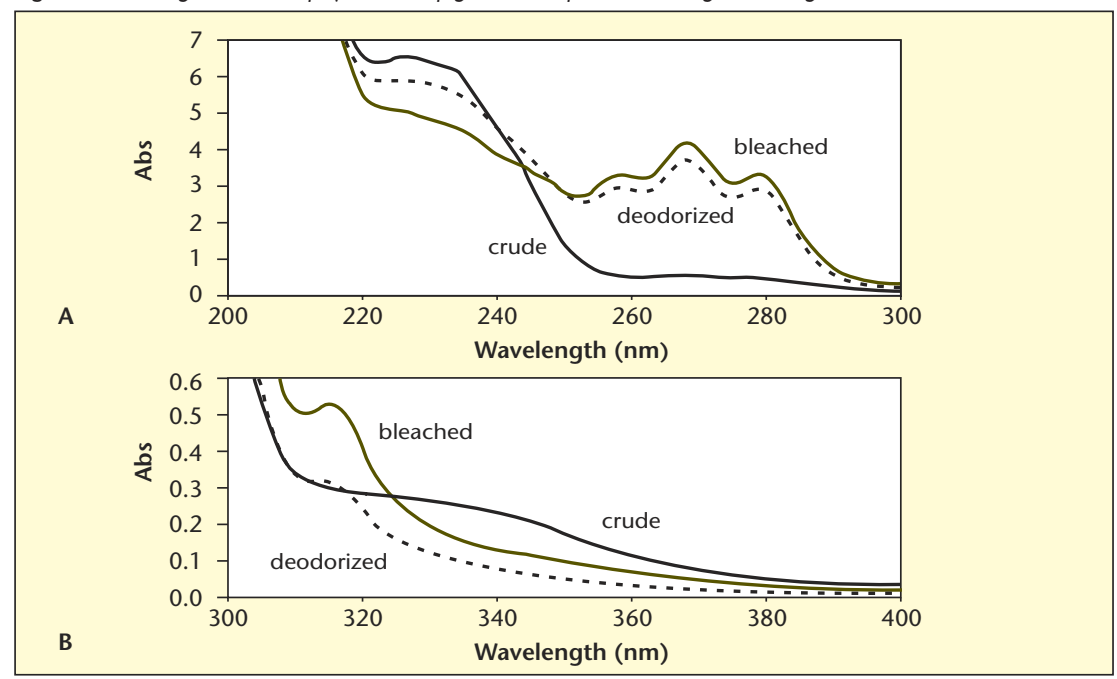

Figure 11. UV-VIS spectra. A) UV absorbance $1 \%$ solution in hexane. B) UV absorbance $5 \%$ in hexane. tion conditions. The trans isomer formation has been proved to follow first order kinetics, depending on the temperature and the time. The linolenic acid has 13-14 times more sensitivity for trans isomer formation than the linoleic acid. In the case of linolenic acid the degradation also should be taken into account $[12,13]$.

Based on the laboratory and pilot scale kinetic study a kinetic model has been established. Using this kinetic model the trans isomer formation can be predicted for each deodorizer conditions.

Figure 13 shows the calculated theoretical values. It is clear from this calculation that mild condition, e.g. keeping temperature below $240{ }^{\circ} \mathrm{C}$ is necessary to meet the low trans requirements. Total trans below $1 \%$ in the case of sunflower oil, below $1.5 \%$ in the case of soya and rape oil is the usual limit in the trade, but in this calculation we used more strict demand: which is more specific for fatty acid composition. We defined the degree of isomerization (DI) and it should be max. $5 \%$ of the total linolenic acid and max. $0.7 \%$ of the total linoleic acid. Further to keep the temperature and the time in the optimum condition the design of the deodorizer is also important. Any hold up and/or local overheating can cause higher isomerization than predicted from the model.

The constructors of deodorizers follow the trend and propose new generation equipments with special, more flexible design like packed column or using pre strippers, adoptable resident time...).

\section{Conclusions}

Integrated crushers/refiners have all the tools to run effectively and safely high capacity one line physical refineries.

There are improved processes and equipment to use mild process and to improve economy.

There are some new techniques in the innovation pipeline for future applications: like membrane degumming, membrane refining, use of biocatalysts, new seed pretreatment, extraction processes, new analytical techniques, on-line control possibilities.

Crushers/refiners and equipment suppliers should continue to work together to meet further challenges.

Acknowledgements. I would like to thank to all my research and development colleagues in Bunge/Cereol/Lesieur for their contribution and all my engineer colleagues working in the plants and being interested in and contributing to the success of plant trials. 


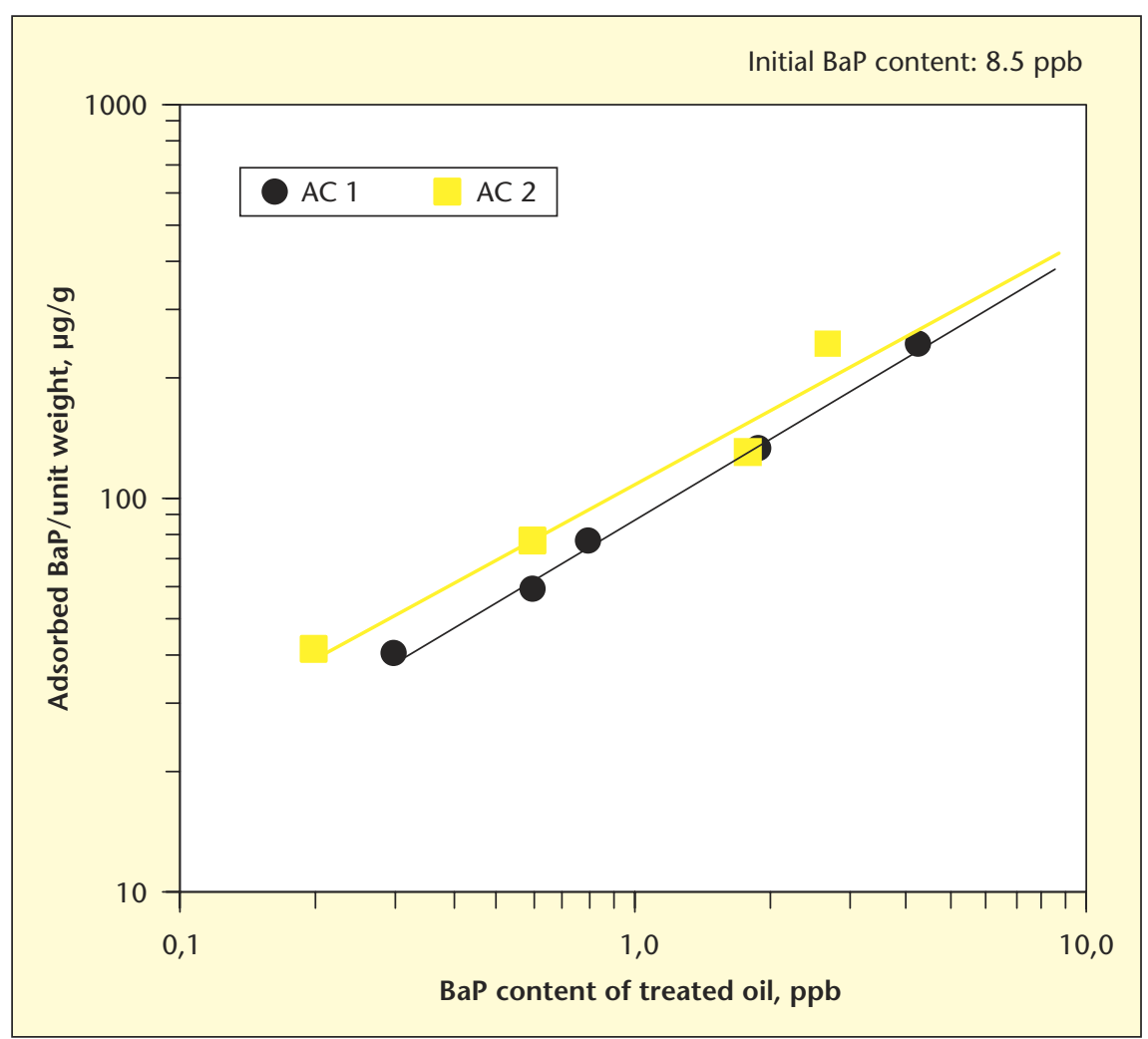

Figure 12. Active carbon isotherms.

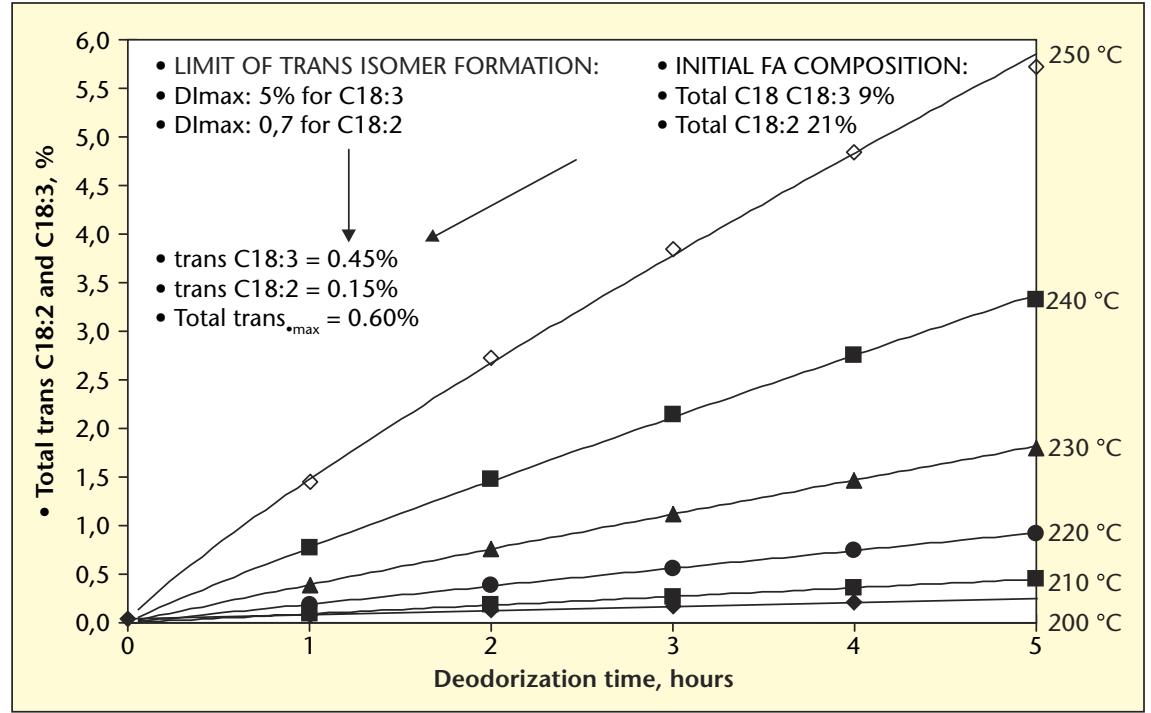

Figure 13. Theoretical values of total trans C18:2 and C18:3 content of deodorized oil.

\section{REFERENCES}

1. KŐVÁRI K, DENISE J, KEMÉNY ZS. Physical refining of sunflower oil. OCL 2000; 7(4): 305-8.

2. RODENBURG $M$, et al. Entscheleimungsverfahren. Assignee Krupp European Patent. 1993; 473895 (1992). US patent 5, 239096.

3. CLEENWERCK $B$, et al. Process for the continuous removal of gum phase from triglycerid oil. Assignee: NV. 1992; Vandermortale European patent. 507363.

4. AALRUST E, et al. Enzymatisches Verfahren zur Verminderung des Gehaltes an phosphorhaltigen Bestandteilen in pflante u. Herischen Ölen. In: Assignee. Röhm GmbH European Pantent. 1992; 513709.

5. RIMGERS, SEGERS JC, et al. Degumming process for triglyceride oils. In: Assignee: Unilever US Patent 4. 1977; 049686.

6. SANDE, et al. Method for refining glycerid oils. In: Assignee: Unilever European Patent. 1989; 348004.

7. DIJKSTRA AJ. Process for producing degummed vegetable oils and gums of high phosphatidic acid content. In: Assignee: NV. Vandemoortele European Patent. 1986; 195991.

8. JAMIL $S$, et al. Procédé de dégommage d'un corps gras et corps gras ainsi obtenu. In: Assignee: Tirtiaux WO Patent 95/00609. 1995.

9. DAHLÉN JAH. A New Way to Produce Crude Rapeseed Oil with and Extremely Low Content of Nonhydratable Phosphatides. In: World Conference on Oilseed and Edible Oil Processing. Istanbul 6-10 Oct. 1996; Proceedings Vol. II. Section 2.

10. KŐVÁRI K. General consideration on bleaching of fats and oils. Lipid Technology Newsletter 2003: 131-5.

11. CHAPMAN DM. Nature and Chemistry of Fix Colour. In: AOCS Annual meeting. 1994.

12. HENON G, et al. Deodorization of vegetable oils. Part 1: modeling of geometrical isomerization of polyunsaturated fatty acids. JAOCS 1999; 76: 73-81.

13. KEMÉNY ZS, et al. Deodorization of vegetable oils: prediction of trans polyunsaturated fatty acid content. JAOCS 2001; 78: 973-9. 